\section{THE SCIENTIFIC WORKS OF LORD RUTHERFORD OF NELSON}

The Collected Papers of Lord Rutherford of Nelson, O.M., F.R.S.

Vol. 1: New Zealand-Cambridge-Montreal. Published under the Scientific Direction of Sir James Chadwick, F.R.S. Pp. $931+12$ plates. (London: George Allen and Unwin, Ltd., 1962.) 126s. net.

$\mathrm{T}$ any age there are but a few scientists who are 1 important enough to make it both useful and fitting that all their scientific works should be collected and republished. Ernest Rutherford is certainly one of these rare beings. This first volume of his collected. works covers the period from 1894, when the twenty. three-year-old student of Canterbury College, Christchurch, New Zealand, started experimenting on the magnetization of iron by high-frequency discharges, to the end of his time at McGill Univerisity, Montreal, in 1907. By then Rutherford had completed the work on radioactivity for which he was awarded the Nobel Prize for Chemistry the following year. Juring these thirteen years at Christchurch, Cambridge and Montreal, Rutherford published 65 papers, an average of 5 a year, with an avorage of 14 pages ench-a remarkable output. His earliest papers showed his gift for finding the simplo and direct experimental approach. When he suspected that the highfrequency eloctric discharge only magnetized a thin outer layer of a steel needle, due to tho skin effect, he just dissolved off the outer layer with acid while watching the magnetization of the needle with a magnetometer: the magnetization first disappeared and then returned weakly in the opposito sense, so domonstrating a surface layer magnotized one way and an inner layer magnetized the other.

Rutherford's arrival in Cambridge in 1896 coincided with the hugo impact on the scientific world of the discovery of radioactivity by Becquerel, and of X-rays by Roentgen. Ho immediately started, in close collaboration with J. J. Thomson, the study of the process of ionization of gases by X-rays, and made his first important contribution to physies by his measurement of the mobility and rato of recombination of ions. He turned his attention to radioactivity as soon as he arrived in Montreal as MacDonald professor at MeGill in 1899, at the age of 28. From then on his scientific life's work was settled: all but one of the papers in this volume relate to radioactivity; this is a paper in 1903 entitled "A Ponetrating Radiation from the Earth's Surface", in which he surrounded an electroscope with 5 tons of lead and deduced the existence of a radiation which was more penetrating than any known rays from radioactive substances: this was, of course, one of the early investigations of what later became known as cosmic rays.

Tho high points of this Montreal period were the discovery of thorium emanation, the elucidation with Soddy of the transformation theory of radioactivity, and the detailed study of the alpha particle; for this particle he was later in life to display an almost paternal affection. His wider interests are shown by a 'popular' article in Harper's Magazine in 1905, entitled "Radium as the Cause of the Earth's Heat", and two years later a lecture to the Royal Astronomical Society of Canada, "Some Cosmical Aspects of Redioactivity": both make good reading to-day and show Rutherford's interest in geophysics and astronomy.
Sir Edward Appleton has contributed a valuable essay on "The Young Rutherford", and H. L. Bronson and Otto Hahn have told of the timo at Montreal.

The second volume will cover the Manchoster period, 1907-1919, the third the Cavendish period 1919 to his death in 1937 , and the fourth will contain miscellaneous papers, lectures and letters, togother with a short biography.

The scientific world is indeed indebted to all those who made this great publishing venture possible: the sciontific editor, Sir James Chadwick, the publishers, George Allen and Unwin, and Dr. Panl Rosboud, who conceived the project. Generous grants from the Government of New Zealand, the National Research Council of Canada, and the Leverhulme Trust in Britain have greatly assisted publication. Herc is a 'must' for every library, and a 'should' for many individuals.

P. M. S. Blackett

\section{PHYSICAL METALLURGY IN THE SEMICONDUCTOR FIELD}

Metallurgy of Elemental and Compound Semiconductors

Proceedings of a Technical Conference, Boston, Massachusetts, August 29-31, 1960. Edited by Ralph O. Grubel. (Metallurgical Society Conferences, Vol, 12.) Pp. xi + 494. (New York: Interscience Publishers, Ine; London: Interscience Publishers, Ltd., 1961.) 13 dollars ; 988 .

7 HE fly-leaf of this book identifics the sponsors of the conference, of which it reports the proceed. ings, as the Semiconductors Cormmittee of the Institute of Metals Division, the Metallurgical Society, and the Boston Section, American Institute of Mining, Metallurgical and Petroleum Engineers. It is a ploasant change to reviow a book dealing with the metallurgy of semiconductors, as distinct from the solid-state physics approach, although the fundamental background is reviewed in each section in such a way that no physicist would quarrel with it.

The main aspects reviewed are the heavily doped materials for Esaki tunnel diodes, and new techniques of crystal growth. In the latter case, dendritic growth and vapour phase deposition aro specifically considered. Part I deals with germanium and silicon for tunnel diodes, with detail of the properties resulting from heavy doping. Patel et al. show that the growth of germanium single crystals from the melt can be achieved with a high degree of crystal perfection by using a high concentration of gallium $\left(3 \times 10^{20} / \mathrm{cm} \cdot{ }^{8}\right)$. The velocity of dislocation movoment under shear stress has been measured to assess the effect of thermal stresses or constraint on the crystal perfection. Arsonic doping of germanium decreases the maximum stross for a given dislocation velocity, while gallium doping raises the stress, both compared with the intrinsic crystal. Interesting results on vapour phase deposition of arsenic and phosphorus on silicon are given in a paper from the General Electric Laboratory, Heavily doped layers, pyramids and rods have been made to grow epitaxially on single crystal substrates, or other nucleation sites.

Part 2 is concerned with dendritic growth, with two excellent chapters on fundamentals of such growth. The problem of solute segregation is covered by two further chapters and a final one with the role of surface tension in crystal pulling. Some beautiful 